\title{
What lies beneath
}

\author{
The mid-ocean ridges mark the lines along which the Earth is turning itself inside out through the \\ process of plate tectonics. Advances in technology are helping to reveal the intricate details of the \\ magma systems that feed the rifting process.
}

The deep ocean has long been a source of fascination, not least because of its inaccessibility. Only in the nineteenth century was the naive assumption that the ocean basins are like bathtubs - deepest in the middle, and shallow near the coasts overthrown by measurements made by scientists on board the HMS Challenger. Using the crude method of dropping weighted ropes over the side of their vessel, they discovered relatively shallow depths in the middle of the Atlantic Ocean, the first hints of a mid-ocean ridge.

Since then, the mid-ocean ridges have been identified as a global system of volcanic activity, where oceanic crust is generated from upwelling molten mantle rock. Occasionally, the rift system extends on land to areas where new ocean basins will eventually appear. About 70\% of Earth's mid-ocean ridge system has been mapped (http://ocean-ridge.ldeo.columbia.edu/ index.html), but the shape and geometry of the magma systems that underlie the rifts and supply new oceanic crust are less well known. Simple models attempt to predict the shape and depth of the volcanic plumbing system by assuming that magma chamber geometry reflects a balance between the speed of plate separation - characteristic for a given section of the mid-ocean ridge system and the supply of magma. Ridges are thus broadly classified into slow- and fastspreading systems, with a range of plate separation between about 1 and $20 \mathrm{~cm}$ per year. But three Letters and a Review article in this issue imply that the volcanic plumbing system is sensitive to a larger variety of factors, and a classification by spreading rate may be less useful than has been thought.

Specifically, fast-spreading plates are expected to be characterized by high heat fluxes, high rates of magma production, fast magma cooling rates and a shallow, narrow and confined magma chamber. However, Canales et al. (page 279) found an intricate network of magma bodies at the fastspreading East Pacific Rise, as well as the expected shallow and elongated chamber at the hot rift axis. The network was

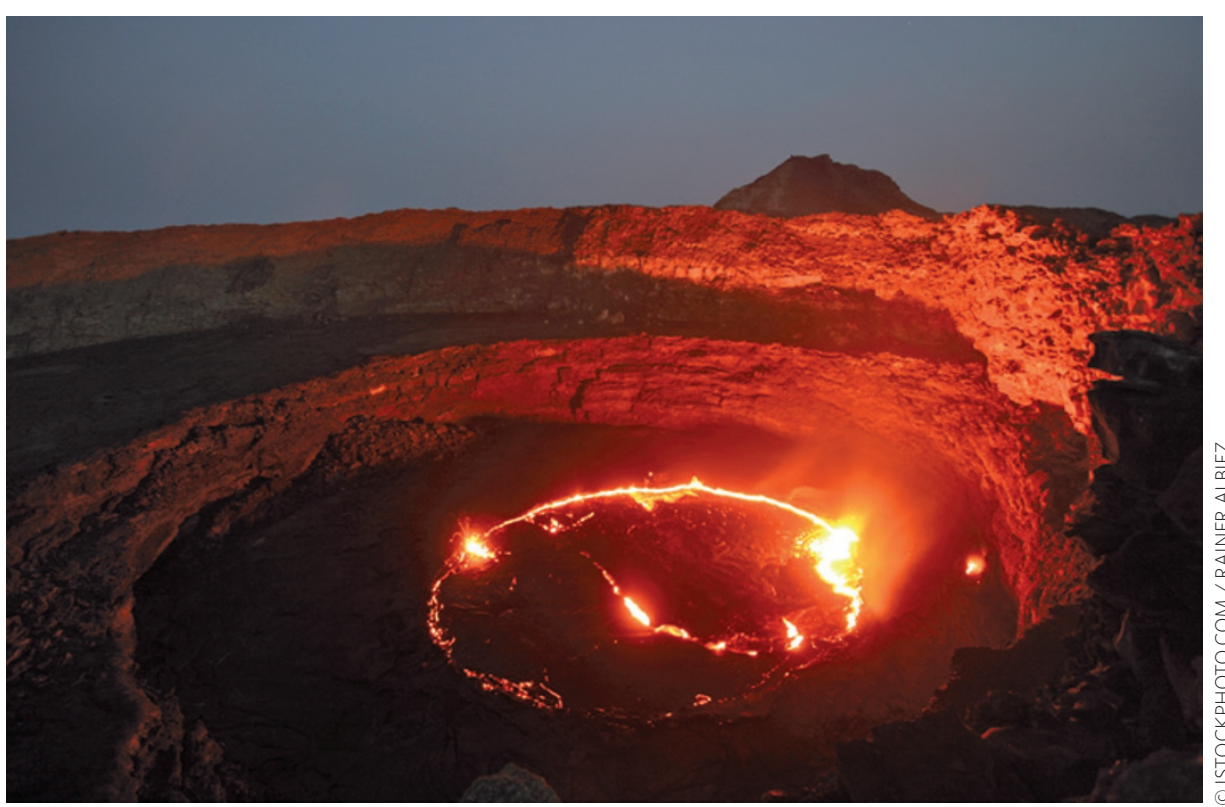

distributed over an area up to 8 kilometres from the axis, in parts of the crust that had been thought to be quite cool.

Nor could the anticipated fast cooling rates be confirmed for the East Pacific Rise at a closer look: probing minerals in a different section of the ridge, Rioux and colleagues (page 275) found that it took the magma a similar length of time to cool in this fast-spreading setting as had been inferred earlier for the slow-spreading Mid-Atlantic Ridge (C. J. Lissenberg et al. Science 323, 1048-1050; 2009).

The slow-spreading ridge in Afar, East Africa - although a somewhat special case because it is has not been inundated by seawater yet - does not conform to expectation either. Rather than low heat fluxes and a deep broad magma chamber, Pagli and colleagues (page 284) diagnose just the type of elongated narrow chamber that had been associated with fast spread. In a Review article that compares this ridge with another slow-spreading centre exposed on land in Iceland, Wright and colleagues (page 242) suggest that pulses of volcanic activity supply the magma.

The unusual setting of these rifts on land instead of under the sea - in
Iceland and Afar could help explain their characteristics to some degree: in a submarine ridge, heat is quickly swept away by the hydrothermal circulation in the rift systems. By contrast, the nascent ridges in Afar and Iceland are missing the ocean's cooling influence and are purported to be affected by hot mantle plumes. The anomalously high temperatures could cause the magmatic systems there to seem more similar to their fast-spreading counterparts beneath the ocean.

The twentieth and twenty-first centuries have seen remarkable advances in technology that have allowed us to peek under the Earth's crust. As ever with the availability of more detailed data, existing concepts of what lies beneath will need to be adjusted. Rather than a simple trade-off between plate spreading rate and magma supply, the geometry of the magma system at spreading ridges seems to be sensitive to a wide variety of factors. The presence or absence of an ocean, a mantle plume and off-axis magmatism that is potentially related to fractures in the crust, can all play a central role in shaping the evolution of the Earth's rift systems. 